\title{
Political and Economic Functions of International Sports Events
}

\author{
Görner Karol ${ }^{1 *}$ and Hadzik Andrzej ${ }^{2}$ \\ ${ }^{1}$ Department of Physical Education and Sports, Matej Bel University in Banská Bystrica, Slovakia \\ ${ }^{2}$ University School of Physical Education, Poland \\ *Corresponding author: Görner Karol, Faculty of Arts, Department of Physical Education and Sports, Matej Bel University in Banská Bystrica, Slovakia

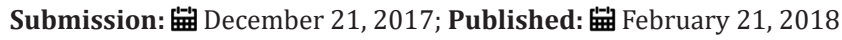

\begin{abstract}
International sport events are not only a phenomenon of sport, but also a tourist one. A simultaneous presence of sport and tourism phenomena which is visible in international sports spectacles allows the realization of various functions. Aim of this work was to show the political and economic function in international sports events on the chosen example of Football Championship organization in France in 2016.
\end{abstract}

Keywords: Political and economic functions; Sport; Tourism; International sports events tourism

\section{Introduction}

International sport events are not only a phenomenon of sport, but also a tourist one. Therefore, events of this type are also an example of sports tourism, making it now one of the most dynamically developing types of travelling and rooting [1]. A simultaneous presence of sport and tourism phenomena which is visible in international sports spectacles allows the realization of various functions. One of the most important functions is political and economic [2], which often determines the willingness to organize such events. Therefore, the aim of this work was to show the political and economic function in international sports events on the chosen example of Football Championship organization in France in 2016.

International Sport Events as an Example of Sports and Tourism

The term "spectacle" is etymologically associated with the theater performance or film presentation [3-5], believes that despite the comparisons sport events differ from theater or music concerts. First of all, surprising decisions or spectacular solutions are more common at sporting events than during other performances. In the case of sports performances it is not entirely possible to foresee everything, as for example during theatrical shows. Sport events are one of those types of special events [6], where sports fans participate, who simultaneously are also often tourists [7]. Sport events have two meanings:

a. Narrower, which is the social event in the form of the struggle of athletes running in the presence of the audience, according to the established rules, b. Broader, including performances and appropriate shows [8].

c. The sports performance is a performance of higher aesthetic, dramatic or emotional qualities, eg. last football match of a wellknown footballer. This modern shape is due to the French culture. In turn, the show is a sports performance which is dominated by the show dexterity, exciting playing with danger, attacking the spectator with a wide variety of physical stimulation [3]. The show is the product of a technical civilization of America. One example was the game of Afro-American basketball players of Harlem.

d. Generally, a sports event "... is a social event accessible for a visual perception of a leisure and entertaining character, occurred because of an organized competition of sports athletes, running in accordance with defined rules (regulations), in which they participate as parties e.g. Interacting players, referees, organizers and spectators creating an audience" [3]. Fans travelling to participate in a tourist's international sport events is defined as fan tourism and is becoming one of the most important, new forms of sports tourism of a passive participation in sports and rooting is an example of such sport tourism not only in Poland $[9,10]$. The contemporary significance of international sports events as examples of sports tourism is conditioned by:

e. Geographical range of the sporting event,

f. Character,

g. Organization,

h. Duration, repetition and

i. Characteristics of the participants [11]. 
One of the most important is the geographical range of the sporting event which, according to the so-called pyramid sport events theory divides this type of an event into a global, international, national, regional and local (Figure 1). Only the show standing high above the "pyramid" is an example of sports tourism and allows the implementation of a number of functions, particularly, the political and economic ones (e.g. Olympic Games or the World Cup or European Championships in football).

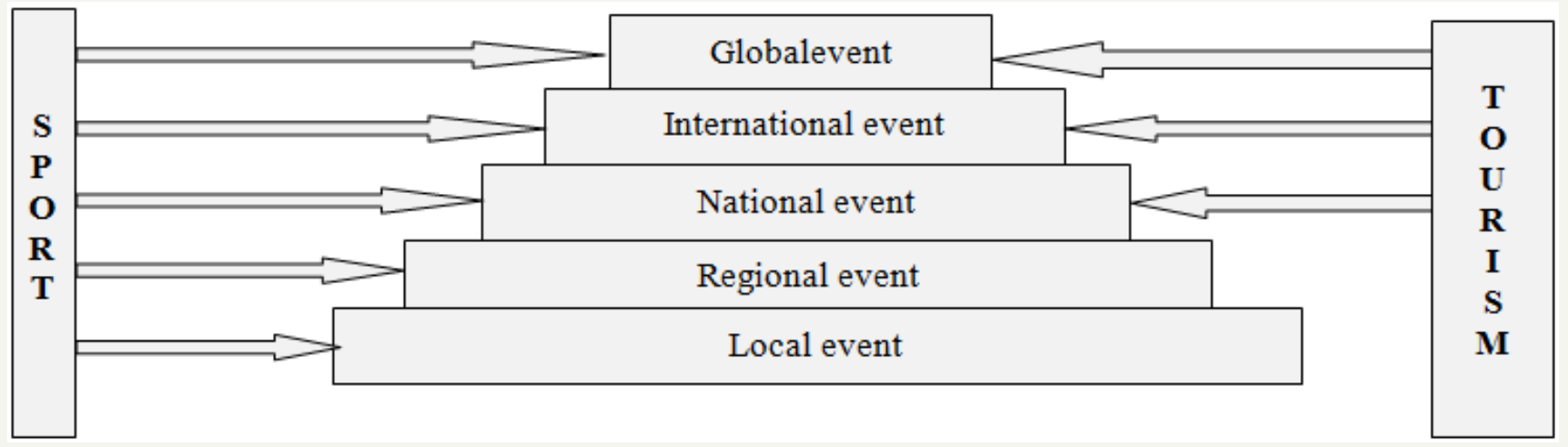

Figure 1: Pyramid of sports events.

Functions of Political and Economic International Sporting Events

\section{An example of the European championship in football}

In tourism of international sports events the created functions result from the diversed connections and relationships, which are formed at different levels of socio-economic development [12]. Today, a number of functions is attributed to international tourism shows of recreation, because they affect a large number of spheres of human life, causing certain effects and focus on areas: economic, socio-cultural and spatial and environmental.

Generally in tourism at these planes the following functions are created:

a. The educational function,

b. The leisure and health function: leisure function, health function,

c. The ethnic function,

d. The training function: cultural education, development of environmental awareness,

e. The economic function,

f. The political function

g. The space development function: urbanization, development of the natural environment [2].

Characterizing sport events lists carried out by the events of this type of social functions [3] (Figure 2).

Economic and political functions are one of the most important, especially for athletes, organizers and areas and the implementation of sport events [13]. The political function concerning international tourism of sports events, allows you to pursue different political objectives of the State, namely:

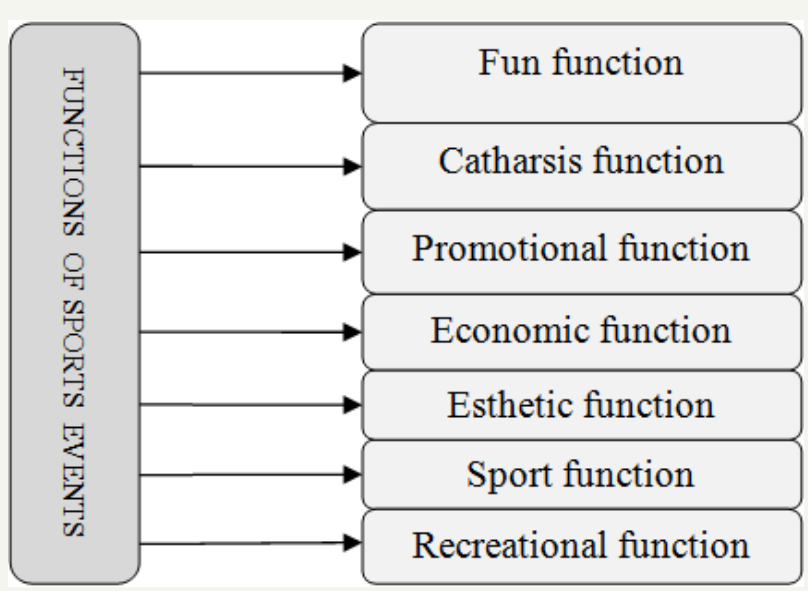

Figure 2: Functions of sports events.

a. Shaping the image of the country,

b. Appropriate nature and scope of relations with other countries,

c. International cooperation,

d. Integration processes,

e. $\quad$ Peace policy of the concerned country [2].

In turn, the economic function is the result of a consumer nature of international sport events, which are simultaneous product of sports and tourism. Widely understood consumption of the product under consideration causes numerous implications in the management [14]. Looking at tourism as a part of the national economy, from the macroeconomic point of view this economic function can be divided into:

a. Creative function-associated with an increase in the share of tourism in gross domestic product (GDP),

b. The function of service-on the growing importance of tourism services in the management and creation of new jobs. 
Sports events have the potential to impact on the economy of the area, especially as experts underline, mainly through promotional effects on the economy of developing countries including Poland and Slovakia. Germany, which organized the football World Cup in 2006 spent around 1.4 billion euros on this investment in reconstruction and construction of new stadiums. Despite such high investment costs, the event has contributed to a number of economic benefits [15]. For example, thanks to the organization of the World Cup economic growth: in the tourism industry with a surplus of 300 million euros and in trade, which recorded an additional 2 billion euro turnover took place in Germany.

The costs incurred by the fans going to great sporting events have an impact on economic effect for the area. If traveling fans purchase their services connected with the events of the type of the Olympic Games, World Championships, it may cause this effect by "pumping" of the economy of a country or region, 2005 [16]. Those measures, regardless of the "national" cash flow, "forced" implementation of the goods and services, including investment and tourist sports. Therefore, the phenomenon of adjustment in aggregate supply is created, resulting in an increase in Gross Domestic Product (GDP).

According to growth of the analyzed macroeconomic rate of at least $1 \%$ already having an impact on the economic development of the region, or even country [17]. This ratio is referred to as the socalled perceptibility threshold of influence in the economy, with the arrival of foreign fans. For example, the organization of the Olympic
Games in Seoul (1988), Atlanta (1996) and Sydney (2000) resulted in GDP growth respectively in the mentioned cities with $1.4 \%$, $2.41 \%$ and $2.78 \%$. In addition, the organization of major sporting events often contributes to an increase in the number of new jobs. In the above-cited Football World Championship in Germany it was recorded that the labor market increased by more than 50 thousand places, mainly in tourism and security services.

The latest report of the Institute of Tourism showed that in Poland in connection with the European Championships in football some direct effects could be already seen. For example, fans expenses during Euro 2012 were higher than the forecasts included in the so-called Impact Report [18]. Expected fans expenditures for a total of 845 million Polish zlotys, and foreign fans during the three weeks of the football Euro spent in Poland 1.12 billion Polish zlotys [19]. Thus, tourists expenses were 33\% higher than expected before the analyzed European Championships. On the other hand, there are also indirect effects. It is estimated that the organization of the European Football Championships by improving the image of Poland will contribute to the fact that Poland is annually visited by 500 thousand foreign visitors more than ever before, which will give the income from arrivals of foreigners in 2020 of about 4.2 billion Polish zlotys higher than now [20]. While comparing the year 2011 (before the analyzed event) and a year 2012 (the year the Euro took place) and from 2012 to 2013 there was an increase in arrivals of foreign tourists respectively $11 \%$ and $7 \%$ (Piotrowski, 2014). In the literature, this type of socio and economic impacts are part of the so-called theory of Barcelona effect.
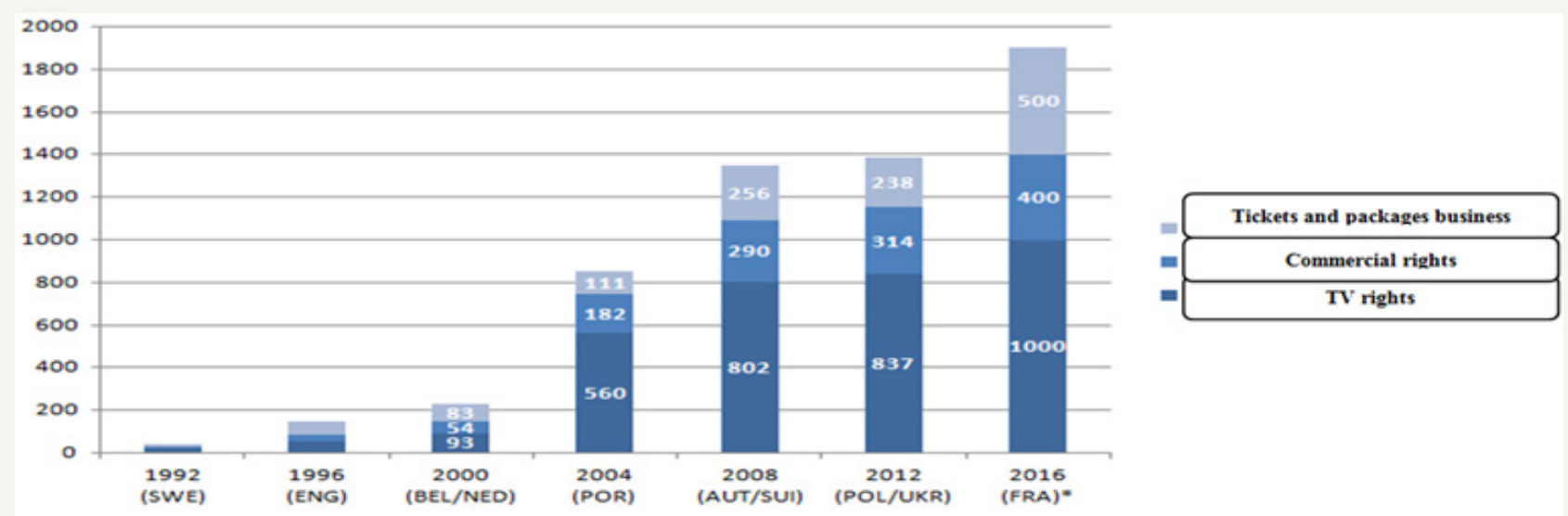

Figure 3: The chart below shows the income from each Euro football in the years 1992-2016.

In 2016, there were two major international sport events, when the sports and tourism phenomenon could be seen at the same time. These were the Olympics in Brazil and UEFA European Championship in France. European Football championships in France were selected due to the willingness to compare it with the above-described European Championships in Poland and Ukraine in order to add the following considerations. Economic forecasts of organization of ME in France define the revenues of the Union of European Football Associations (UEFA), even to the amount of 1.9 billion EUR in the [21]. Of which 1 billion has come from the sale of television rights, 400 million from the sale of the commercial rights (sponsorship), and 500 million from ticket sales and business packages (Figure 3).

According to estimates, the income of Euro in France is supposed to be $37 \%$ higher than income of Euro held in Poland and Ukraine, and twice higher than those in Portugal in 2004 [21]. A significant increase in income is due to changes in the system of play. For the first time in the history of the tournament as many as 24 teams attended the tournament (in 1996 there were 16). In total, there were a total of 51 matches, which were about 20 meetings more than during the European Championships in Poland and Ukraine. The largest increase was recorded in revenues from ticket sales 
and business packages. In 2012, the fans in the stadiums totaled 1.4 million, and in France it was about 2.5 million. In addition, there was an increase in the segment of commercial rights, where the main source of influence is sponsorship agreements .

In turn, the political function of ME in France must be perceived differently than the examples from the literature describing for example the Olympic Games in Moscow in 1980 or in Sochi in 2014 . The political function was seen there by the "prism" to show the size and strength of Russia as a state. The organizers, these kinds of countries wanted to spread socialist ideology, propaganda of strength and size, also through competition in the medal standings. Of course, European Football championships in France and the earlier, including in Poland and Ukraine, have shown the state as the organizer, but mainly from the side of his promotion and improvement of the image (branding). It should also be remembered that France wanted to tell the world that the terrorist attack a year ago made the country even "stronger" and France does not fear carrying out a safe event, which fully succeeded.

\section{Conclusions}

Analysis of selected aspects and examples of creating economic and political functions of tourism international sports events allows the following conclusions:

1. The great global sport events described in the literature as "short-term events with long-term consequences for cities that organize them" [22] allow to implement political and economic functions, which are often linked.

2. Political and economic Functions are one of the most important created by tourism of the international sport events.

3. The political function can take a different nature (propaganda, "strength", spreading the ideology), and in the case of Football Championship example in France was primarily the creation of the image of the state and show the "strength" to the Islamic State terrorists.

4. Economy function is associated with the positive effects of the economic organization of international sports events, which shows an example of the analyzed European Football Championship. However, in the literature there is no unanimity as to the economic effects. There are authors who think that international events are a source of positive economic effects [1], but there are also those who claim that such events bring economic losses.

\section{References}

1. Kazimierczak M, Mośko E (2013) Sport tourism-specificity and development trends. Turistica foil (28): 1-5.

2. Panasiuk A (2007) Ekonomikaturystki, Warszawa: PWN.
3. Matusewicz C (1990) Sport spectacle. Psychosocial analysis. AWF, Poland, p. 114.

4. Kosiewicz J (1998) Sporting event and Aleatorik: coincidence and scheme. Kultura Fizyczna 52(1-2): 18-20.

5. Sahaj $\mathrm{T}$ (2007) Historical and social study of cheering phenomenon. AWF, Poland, pp. 42-64.

6. Getz D (2008) Event tourism: Definition, evolution, and research Tourism management 29: 403-428.

7. Shank MD (2002) Sport marketing: strategy prospective. Price Hall, New Jersey, USA, p. 426.

8. Klisiński J (2008) Marketing in sports business. WSZEiA, Bytom, Poland.

9. Brumm K (2012) Fanoturystyka. Sport fans in a positive light. Poznań, Poland.

10. Szczechowicz B (2012) Physical culture as a source of the value of a touristic and empiric production study. Warszawa, p. 287.

11. Alejziak W (2008) Great sports events as a factor of competitive struggle on the global market. In Tourism as a factor of increasing the competitiveness of regions in the era of globalization. Poznań, Poland, pp. 52-66.

12. Afonin A(2012) Economics of tourism. Contemporary issues. Warszawa, pp. 12-32.

13. Hadzik A (2010) Tourism of great sports events in the era of globalization. Tourism economy in the $21^{\text {st }}$ century. PoznańS (19): 237-246.

14. Hadzik A, Bartik P, Görner K (2012) The European Football Championships in Poland and Ukraine as one of the most important sports spectacles in 2012. Country competition after the European Championships 2012. Józefów WSGE (2): 183-195.

15. Hadzik A, Sawicki Z, Bartik P, Görner K (2015) Sport tourism Theoretical and practical aspects. FHS-print (1): 86.

16. Golembski G (2005) Compendium of knowledge about tourism. Warszawa (PWN), Poland, p. 433.

17. Łazarek R (2004) Economics of tourism. Warszawa (WSE), Poland, p. 232.

18. Borowski J (2010) The impact of the organization of the European Football Championship UEFA EURO 2012TM on the Polish economy. Warszawa (MST), Poland, p. 110.

19. Piotrowski M(2014) Euro 2012 The Polish Effect: Growth, Image \& Tourism Legacy. Ministry of Sport And Tourism of The Republic Of Poland, OECD, Polish Tourist Organization.

20. Klisiński J(2008) Marketing in sports business. Bytom, Poland.

21. UEFA European Championships revenue from 1992 to 2012.

22. Ritchie JR, Crouch GI (2000) The competitive destination: a sustainable tourism perspective. Tourism Management 21 (1): 155-156. 
For possible submissions Click Here

Your subsequent submission with Crimson Publishers will attain the below benefits

- High-level peer review and editorial services

- Freely accessible online immediately upon publication

- Authors retain the copyright to their work

- Licensing it under a Creative Commons license

- Visibility through different online platforms

- Global attainment for your research

- Article availability in different formats (Pdf, E-pub, Full Text)

- Endless customer service

- Reasonable Membership services

- Reprints availability upon request

- One step article tracking system 